\title{
Creating My Own Way of Being a Psychologist
}

\author{
Katrin KULLASEPP \\ Tallinn University
}

The purpose of this article is to present results of an ongoing longitudinal qualitative study that aims to chart the dynamics of professional identity construction of Estonian psychology students over the period that embraces their studies of psychology in a bachelor's program and two years after obtaining a bachelor degree. The construction of an identity is discussed from socio-cultural perspective, and in terms of the semiotic mediation approach. To investigate dynamics in intra-psychological level, the dialogical self theory (Hermans, 1995) was applied. The results show how the Self $<>$ Self and Self $<>$ Other dynamics set up differentiation of inherently inconsistent parts of the Self ("being myself" $<>$ "being a psychologist"), and that the entry into professional role entails inter-individually different linkage of the features of personal culture with different aspects of the expected role of psychologist.

Key words: professional identity, dialogical self, image of psychologists, meaning making

\section{The professional identity of psychologists in the focus}

In the extensive studies of professional identity the importance of self-definition in assuming a professional role has been pointed out. It is emphasized that socialization in professional role expectation management does not only require from a learner the acquisition of new knowledge and skills but also involves the development of self-identity components (Hall, 1987). In the research on professional identity of psychologists, the focus is, for example, on the suitability of the identity for occupying this role, including moral development, emotional stability, and the need for assessing personality profile when being admitted to postgraduate studies and awarded a degree (Johnson \& Campell, 2002). Bruss and Kopala (1993) claim that psychology studies mean being faced with a new environment, which is perceived by students as challenging and leads to changes in the self of an individual. For example, attitudes of the future psychotherapists may change, and they may develop an internal need to behave morally, ethically (VanZandt, 1990).

However, it is pointed out that studies on identity often focus on the outcomes of development, e.g., acquired values. Albeit, as the result of the orientation to outcomes, the process of the emergence of changes, which of course, is detectable on the basis of the outcomes, remains overlooked. It is thought that while learning about a continually evolving system, it is important to focus on the process of emergence of new forms as the most central characteristic of the changing phenomenon, and in order to understand psychological phenomena, the formation of that phenomenon has to be considered (Abbey \& Diriwächter, 2008). This level has not been addressed by studies explaining identity for- 
mation through a constructive individual-environment relationship and through inter-individual comparisons.

The question that is addressed in the current article concerns the professional identity construction of psychology students. We focus on the process of linkage of personal culture with social role expectations, and on the dynamics of the emergence of subsystem at the intra-psychological level.

\section{Socio-cultural becoming: institutionally framed and uniquely constructed identities}

According to the socio-cultural perspective, the personal and social worlds are dynamically interdependent. As the result of dialogical relations between person and its surrounding, humans' psychological functioning "carries" marks of the cultural context within which their becoming oneself unfolds in time. It also concerns construction of identities. In this study an identity is conceived of as a complex developmental process that is coordinated at the levels of social-institutional representations (e.g., knowledge about what a psychologist is reflected in curriculum) and that of internalized personal representations. While constructive processes of internalization-externalization exclude the isomorphism between collective and personal cultures (Valsiner, 2001), it is expected that there are $\mathrm{N}$ number of ways of being and becoming a psychologist even if the general background of psychologists-to-be is the same.

From the starting point of semiotics (Lotman, 1990), professions can be viewed as signs-as they are talked about through abstracted meaning complexes. The notion of a psychologist is, thus, a meaning complex with which we can operate in our discourses. According to the semiotic mediational perspective, the result of a dialogue between a person and his/her social surrounding is the adap- tion or creation of new meanings which generalized versions-signs with sufficient abstractnessbecome promoter signs that canalize the action flavoring one's activity with value-orientation (Valsiner \& Rosa, 2007; Valsiner, 2007). Such sign—semiotic entity-guides one's becoming a professional in the course of psychology education, while offering semiotically mediated cultural material for construction of idiosyncratic self-understanding (Vygotsky, 1987).

The application of the dialogical self theory (Hermans, 2002) within the present research topic enables to shift attention to the intra-psychological dynamics and to describe professional identity construction in term of I positions. The dialogical self theory (DST) is a recent direction of research within the socio-cultural perspective about human social mind (Hermans, 2001). According to DST, the dialogical self is the semiotically self-regulating self that consists of varied relatively autonomous I positions that create "voices" which make it possible for I position to join the inner dialogue, and contribute a specific perspective to that ("tells its own story"). The appearance of a new I position can be due to any sort of personal experiences (e.g., reading the book) that can make certain identities more desirable than others.

The Trajectory Equifinality Model (TEM) (Sato, Yasuda, Kido, Arakawa, Mizoguchi, \& Valsiner, 2007; Sato, 2009) is a new direction in the contemporary psychology that emphasizes the multiplicity of human life course trajectories. TEM brings into the psychology the notion of history, and stresses the idea of equifinality meaning that the same state may be reached from different initial conditions, and in different ways in the course of time. Individual trajectories of development of open systems may converge at the equifinality point (EFP), but 
after passing through this point they diverge. Within the EFP, changes that take place can be similar in general lines, but never the same. All psychology students who go through a standard curriculum come from a variety of life trajectories that had initially led them to want to study the psychology, and after studies in bachelor's program their trajectories diverge again into the plurality of personal life courses.

\section{Method}

\section{Participants}

The ongoing study is positioned within the framework of idiographic science (Molenaar, 2004) as it enables to look at the intra-individual variability in time. There is an opinion that treating individuals as a homogeneous group and comparing different groups is not the most suitable way of learning about the developmental process of psychological phenomena (Hamaker, Dolan, \& Molenaar, 2005). In consistency with the theoretical frame and with the perspective of cultural historical approach in the sampling, the concept of historically structured sampling (HSS) has been taken into account (Valsiner \& Sato, 2006; Sato et al., 2007). HSS is a method of sampling that intends to select individual cases through consideration of their historical trajectories moving through a common temporary state (equifinality point-EFP). HSS makes it possible to contrast individuals who have arrived at the present state through different life course trajectories.

In the staring point of the study in 2004 the sample consisted of a cohort of psychology students $(n=23)$, who were admitted in the same academic year. Participation in the study was voluntary. All of the twenty five first year students were invited to join the study, twenty three of them decided to par- ticipate. Twelve participants exited the study for various reasons in different phases of the study. Eleven of the full list of students who started their psychology studies had been interviewed over five years once in a year (in 2005, 2006, 2007, 2009). In 2008 students wrote the retrospect. This period embraces their studies of psychology in the bachelor's program and two years after obtaining a bachelor degree. Six of these eleven participants continued studies in the master's program, five of these six preferred counseling/clinical specialization, and one chose the field of organizational psychology. Three of the eleven students preferred for different reasons not to continue studies in master's program the year following the obtaining of a bachelor degree, but their jobs were linked with counseling/clinical psychology (e.g., employed by a counseling center). Two of the eleven students distanced themselves from the field of psychology (in 2009 they did not have any intentions to move back to the field).

\section{Procedures}

Students filled out open-ended questionnaires to elicit information about the influence of studies of psychology on their lives, about possibilities to perceive a new formative aspect of the self when socializing with others, about other people's attitude toward them as a psychology student and so forth. Interviews were done to elicit information about the perceived differences in students' behavior, and thinking over the years. Students were asked to describe what a psychologist is. For the same purpose the rating scales were added into questionnaire to observe students' understanding of psychologists' distinctiveness/non-distinctiveness from non-psychologist. Particular statements that were to be rated were constructed on the basis of the data collected with interviews. Essays were written by respondents in the first year of studies to 
reveal information about their reasons for preferring to study psychology and dynamics of informal relations due to this decision. After obtaining a bachelor degree, students wrote retrospection about how studies of psychology had influenced their personal lives and activity in professional settings. All questions were expected to reflect the emergence of the I position, "I (me) as a psychologist" and intra-psychological dynamics of the identity formation as the result of the movement into the new environment of institutional representations.

\section{Results and Discussion}

\section{Taking the shift in construction of personal culture}

In line with the theoretical framework, it was expected that transposition into the new social position of psychology students and their entry into the new environment of the institutional representations reflect in the creation of a personal culture. Based on students' reports, their representations of a psychologist became more heterogeneous through differentiation and qualitative changes by the third year of studies and continued to form after obtaining a bachelor degree.

Examples:

1st year of studies:

Student A: "I had prejudice against psychologists before, now I look at them as ordinary people, I thought that they know how to interpret every movement you do. A psychologist must be in any case trustworthy, others could be."

Student B: "I didn't know anything about psychologists... I think that a psychologist is the person who is interested in reasons of peoples' behavior, they want to analyze, explain reasons, direct people to the right way."

3rd year of studies:
Student A: Most of psychologists don't read minds and are not arrogant, but very nice people. [Psychologists] do not blame hurriedly. Carefulness, honesty, continuity [characterizes a psychologist]. Student B: "One thing is clearer now-if you study psychology, it doesn't mean that you become a psychologist. Psychologists are generally more tolerant. They don't make small problems big in life. They have a higher threshold of stress resistance, and they are more patient. Their ability to express empathy is better, their abilities of analyzing and listening are also better.'

First, when analyzing students' reports, the following groups of characteristics used to reflect an image of a psychologist were identified: personality features (empathic, tolerant, honest, high threshold of stress resistance, etc.), skills related to interactions (listening and self-expression skills), cognitive peculiarity (e.g., analyzing, broad view of life, seeing the aspects in people's behavior in the way others do not).

Secondly, regardless of the acknowledgment of different fields of professional activity ("What kind of type of psychologist? It is so general a term [psychologist]... They work in different fields"), students' responses revealed a tendency to describe psychologists in terms of professional practice and competencies of clinical psychologists/counselors: the personality features that are needed to establish trusting-supportive relations with another person (e.g., empathic, tolerant, honest) were moved into the focus. It should be mentioned that in the first year of studies the utterance "I don't know" (who is a psychologist) was common in students' reports. Some students reported 9 months after commencing their studies that they "haven't thought about that."

Thirdly, students' images of a psychologist were 
Table 1 Descriptions of psychologist

\begin{tabular}{|c|c|}
\hline Personal life & Personality features \\
\hline $\begin{array}{l}\text { "I absolutely agree that compared to others psychologists } \\
\text { should ... } \\
\text { - know better how to solve problems in personal life" } \\
\text { - be better at helping themselves" } \\
\text { - be more satisfied with personal life" } \\
\text { - be better at keeping relationships" } \\
\text { - know how to arrange their lives" }\end{array}$ & $\begin{array}{l}\text { "I absolutely agree that compared to others psychologists } \\
\text { should... } \\
\text { - be trustworthy" } \\
\text { - be tolerant" } \\
\text { - wish to interact and talk with people" } \\
\text { - be interested in others' thoughts" } \\
\text { - manipulate less with people" } \\
\text { - be more moral" } \\
\text { - be happier" }\end{array}$ \\
\hline
\end{tabular}

not rich in detail: the description of a psychologist was limited in characteristics. Students admitted over the years that they have difficulties with answering to the request to describe a psychologist. It is rather unlikely that, for instance, a 3rd year student does not have information needed to construct a detailed picture of a psychologist. Their responses are more likely to refer to the unimportance of depicting the image of a psychologist in detail while becoming a psychologist. It seemed to be sufficient to describe the future role through just a few features relevant for them.

Fourthly, taking into account the results collected with rating scales (Table 1), we can assume that there was a tendency to idealize psychologists when students studied psychology. That tendency seemed to change after the studies in bachelor's program: participants reported in 2009 that their picture of a psychologist had changed. Their feedback to psychologists was more critical. For instance, "it seems that psychologists are ordinary people," "not all of them are so smart as I used to think."

Fifthly, against the background of the construction of the picture of a psychologist, the incorporation of the personal domain with the professional one deserves attention. The data collected with the rating scales in the last year of studies in bachelor's program affirmed students' inclination to extend their role expectations beyond the professional settings that was first expressed in interviews when students were free to depict a psychologist, and later studied by using rating scales. In 2007, 13 students who were about to accomplish their studies in bachelor's program rated the following items with maximum scores ("I absolutely agree that compared to others psychologists should...):

In other words, you as a person should be more effective at organizing your personal life than others (non-psychologists), because you do x-kind of work. Besides the expected effectiveness in interpersonal settings, and at helping oneself, students referred that persons who have the role of a psychologist differ in personality features from non-psychologists.

\section{Dialogue of academic and common sense "voices" in the emerging of "professional culture"}

Representations are continuously under construction. Besides the influences from academic activity in university (e.g., attending classes, seminars), the images of a psychologist were also shaped through professional practice. Some of the reports illuminated clearly the relationship between the personal (professional) experience and the construction of an image. 
Examples:

Participant C (is connected with counseling psychology): "Before I idealized psychologists. They were higher than common people: their values and norms, I thought, were different. Now, as a working person I have realized that a psychologist is first of all a human being who can forget appointments, betray clients' trust, burn out, overwork. Psychologists are common/ordinary people who just have psychological knowledge and skills."

Participant D (2nd week as a school psychologist) "A school psychologist must be friendly, open, so that children have a wish to come to you. The main aim of a school psychologist is to be there for them, to listen to them." (in 4 months, after a conflict situation at work): "Before I thought that school psychologist's role is to be a good person, who is listening, and basically nothing else. That work is not that easy and fun as I used to think."

One more source for the formation of personal understanding about psychologists was revealedinformal relations with non-psychologists. In everyday interactions with friends and acquaintances outside of the academic environment, students became targets of the expectations that contributed to the creation of a personal culture and shaped the meaning of a psychologist. For instance, "you as a psychologist keep secrets, you can't get emotional, you should control yourself in a tense situation." The expectations were accepted or rejected by students. Students disagreed with others' common/ everyday understanding about psychologists (opinions other people hold, as viewed by the students) like "psychologists are analyzing and interpreting others' behavior all the time," "they work only with psychos," and "psychologists have problems with themselves," but tended to control and regulate themselves as they were told to do since "you are a psychologist."

What deserves attention is the fact that the input that fed into the creation of an image of a psychologist comes from the outside of the academic field. And, as data illuminate, common everyday knowledge came across many situations as the basis for self-regulation, setting up the directions of the development of the self: "My friends expect greater understanding. They say 'You are a psychologist, you keep secrets,' and I do [keep secrets] ... [Does it influence you somehow?] Yes, when expectations are higher... you want to maintain expectations. For sure, expectations are higher... I must behave differently.' Personal culture has its roots in collective culture, and becoming/being (e.g., being in the formal relations with client/patient) a psychologist in certain society may reflect in specific sources of tension. The following example illustrates how the traditional knowledge of society and commonsense elicits tension in formal relations (psychologist-client) of professional activity and is involved in intra-psychological dynamics.

Student P (is working as a school psychologist, and continues studies in master's program): "With adults it is more difficult to work. You should control all the time what you are saying. They are hypercritical and start commenting immediately. Maybe I am not able to react in the most right way at that moment. I am not ready for adults... [Why do you think so?] I am young, they are older, and I don't have children, I don't want them to feel that I teach people older than I am. But maybe I am mistaken."

Thus, others' (non-psychologists') common-sense based role-expectations as well as internalized traditional culture-specific knowledge (e.g., hierarchies of domination, parenting) organize students' psychological functioning not only during the pe- 
riod of studies in informal settings, but also in formal relations. The fact that everyday knowledge elicits negatively oriented tension and insecurity in professional settings should call attention of educators of psychologists. These data illustrate that being a professional (psychologist, teacher, etc.) is far more than being a person who "simply" takes a professional orientation to the issue when acting in a professional setting. Being in a professional role means coordinate inconsistent subparts of the self- "me as a person" and "me as a professional."

On the basis of the results presented so far, we can see that among students there is an idea about the difference between psychologist and non-psychologist. Taking into consideration the purpose of the current study, these findings should be discussed in terms of the formation of the future self.

\section{Images of a professional role as feeding into} the construction of a new I position

In line with the socio-cultural theory, representations are thought of as the source of formation of a new I position (me as a psychologist). As our study illustrated, the images of a psychologist set up the direction of the development by suggesting the state of affairs that should be reached, and that a person who intends to become a psychologist organizes her/his intra-psychological functioning according to the internalized social role expectations when entering into the role. The willingness to go through changes made students develop and employ different transfer strategies (Kullasepp, 2008a) to diminish the discrepancy between what is and what should be.

Characteristic of the entry into the role was the tendency to extend the self toward prosocial orientation (e.g., "I became more tolerant"). The participants also indicated a perceived improvement in their interaction skills (e.g., "I am now better at lis- tening"), and changes in their reasoning style (e.g., "I am analyzing more," "I notice more aspects of phenomena"). In some cases the continuity in the creation of an identity and employment of transfer strategies across the years toward the desired direction was found.

As a first year student $\mathrm{S}$ explained (Kullasepp, 2008, 2011):

"Next year I am planning not just to learn, but also understand, so I could use the knowledge in the future. I also want to improve my verbal expression skills."

After the 2nd year of studies $\mathrm{S}$ reported:

"Many students have a problem that they are afraid to perform, I also had that problem before. When we have classes, for example, and some of us must report in front of the class what we discussed, then they all push me to do that. $O K$, I can do it for myself [while] a psychologist must have skills to perform."

In answer to the question what could make the student good at psychological work in the future, $\mathrm{S}$ answered:

"Empathy is probably the most important feature [when doing psychological work] ...I feel so much empathy inside me-Actually I am afraid that I am too empathic. Hope that once I graduate, I can better express myself, now I am not good enough at expressing my thoughts. My resistance to stress is low, I have to change it. Psychologists must love their work, they must give themselves fully, because others' well-being depends on that. They must be more interested in the patient than in themselves." After the 3rd year of studies (the final year of studies in the BSc program), the student works as an educator:

"When I work I can improve my performance skills and skills of verbal self-expression."

As a student in master's program, where $\mathrm{S}$ specializes in clinical psychology and wishes to become a counselor, 
S says:

"A counselor should be tolerant. Those who keep talking, and it is impossible to say something in-between, those who are guided by emotions, are not good counselors." /In retrospect in 2008/ "I became more tolerant, I can see things from different angles, and through others' eyes."

The case of $\mathrm{S}$ also illustrates how the dynamics of an identity is elicited through the institutionally constructed professional role of a psychologist (formal regulations of the professional role like the demand of confidentiality), and guide persons to move beyond the already existing boundaries of the self. As the student $\mathrm{S}$ in her 3rd year of studies of psychology reported: "A psychologist must follow the rule of confidentiality. Actually, not only when doing work, but also in private life, because people tend not to separate persons and their job, they see them as one unit. So, otherwise it will ruin an image of all psychologists and it decreases their trustworthiness."

One aspect of the creation of novelty in identities of psychology students deserves attention. Namely, even if some of the participants linked studies of psychology with some difficulties in life (others' expectations, etc.), the overall influence of studies was perceived as positive, the changes that they pointed to had a positive value in society. Students' answers revealed that they extended (intentionally or not) their selves toward prosocial orientation, and their interaction skills improved. Reported changes also concerned cognitive component of their psychological functioning. How to explain that?

The current socio-cultural (semiotic) approach to identity enables us to claim that the directions of development of the self are set up by personal representation of a psychologist that begins to regulate one's psychological functioning. Thus, it is expected that the internalized sign of a psychologist reflects in the construction of the image of the self. At the same time objective changes in the personality features and skills may, but do not necessarily have to play the role. We assume that the fact of the transposition of the new social position itself, others' expectations, and comments that accompanied this movement, as well as the awareness of participation in the training program, fed into the construction of the understanding of "I have changed." The efforts to be different and to do something differently reveal one's readiness to go through changes, but do not say much about the objective changes. The extension of the self through positive changes when assuming the new role could be explained by self-enhancement theory (Baumeister, 1999) according to which the appearance of positively valued modifications in the picture of the self can be explained by motivation increasing their feeling of personal worth, and thinking well about themselves.

\section{Psychologist-the sign for others}

Semiotically mediated cultural becoming is not only the subject matter of the domain of the intrapsychological functioning and does not occur only "in the mind" of a person. Becoming also embraces the culturally guided psychological functioning between persons (Valsiner, 2007) that places the topic of the creation of the (professional) identity into the frame of interpersonal relations. Semiotic marking enables us to define our own positions in interpersonal networks, and construct relations with the external world.

Informal relations had a part in students' forming understanding about themselves and shaped the context for the construction of an identity. Interactions between persons (expressed expectations, de- 
mands, affective reactions, attitudes, etc.) reveal the images that participants of the interactions hold about each other. The communication brings out social categories used to classify others, providing concurrently the bases for further reactions. If someone's membership of an X group is "uncovered," certain responses are more likely to be displayed. If one says that she is working as a bus driver then it is unlikely that in response to that discovery someone will ask questions about how to increase one's self-esteem. In other terms, when $Y$ is semiotically marked as $\mathrm{Z}$, then $\mathrm{Y}$ will be treated as if he/she were $Z$ (even if $Y$ disagrees). As a consequence, Y's feelings, thoughts and behavior will be affected and can be conceived of as a reflection of the semiotic marking in intra-psychological level. According to Ian Hacking, classification of people leads them to grow into the categories used to define people, and the fact of categorizing of someone can affect him/her who is categorized (Hacking, 2000). Students' answers revealed that due to the transposition to the position of psychology they met others' expectations and suggestions like "be more like a psychologist," "behave like a psychologist," and "do or do not X, Y, Z while you are a psychologist." They were told in everyday settings what they should be/become, and they were treated as if they were different than non-psychologists in terms of possessing certain features, skills, and knowledge. Depending on the conditions, these suggestions evoked positive and negative affective reactions, making them reject or accept social demands.

On the other hand, the students reported that they had intentionally applied professional knowledge in informal interactions with their friends, acquaintances, and family members, and by doing so they found an opportunity to enforce the emerging
I positions, "I as a psychologist."

\section{The new Me-the gateway into the new world of meanings}

Human mind, as understood in the DS theory, is imaginative, which enables acting in terms of AS... IF. That is a crucial feature in the development. The ability to imagine oneself acting as... if he/she were the other (e.g., a psychologist) (Simão \& Valsiner, 2006) makes it possible to approach an issue, event, another person, etc. from different perspectives. Some of these perspectives have emerged by assuming different social roles. That means that one person can make sense of a particular situation in many ways. In that sense, during the formation of new I positions (me as a psychologist) the new approaching style will appear, as well as new meaning complexes are created that relate persons to their surroundings.

\section{The adaptive function of the creation of meanings}

As data show, the new emerging I position "me as a psychologist" in students' self-system reflected in the construction of meanings. According to their reports, it was characteristic of students' experience to be related differently with the surroundings. New meanings of the objective world were created. It was typical in informal as well as in formal settings. Most of the respondents reported on a changed way to see the world that was not in "black and white" any more, and in many cases, attempts were made to apply professional knowledge to make sense of others (e.g., "I don't label people stupid so easily [anymore]... maybe s/he is ill or something...").

By the example of the case of $\mathrm{P}$ (a person who continued studies in master's program and is working for the first year as a school psychologist), we can demonstrate an effort to eliminate tension that grew due to the dissonance between the images of 
a professional school psychologist and the perceived (present) level of professionalism through the construction of a new meaning:

"As a school psychologist I need to learn to take moments of silence as normal when working with children. Silence, the moment when I don't know what to say, is a tense situation for me... When it occurs, I think that, indeed, it should be like that \{silent moments\}, because some people need to think too (when interacting). I don't have to know everything when the teacher comes and asks something. And I think that children also think that the psychologist doesn't have to babble all the time."

As we see, $\mathrm{P}$ is engaged in applying the semiotic devices that are expected to support the elimination of tension in psychologist's role. According to $\mathrm{P}$, the moment of silence that she describes as "the moment when I don't know what to say" refers to something that should not happen when working as an expert. To eliminate tension, $\mathrm{P}$ constructs a new meaning:

something ("silence") that SHOULD NOT happen

$$
\text { becomes } \rightarrow
$$

something that SHOULD happen

\section{("Indeed it should be like that")}

The moment of silence acquires a positive connotation through the construction of the new negatively flavored meaning of "talking all the time" that becomes "(not) babbling all the time..." What is seen as a professional imperfection ("silence") is turned into the congenial, something that belongs to the professional conduct ("Indeed, it should be like that").

So, to feel oneself more professional and to adjust to the role, one can construct meanings that thereafter begin to regulate psychological functioning (e.g., elimination of experienced tension). Moreover, this example demonstrates that instead of improving skills (e.g., doing $\mathrm{X}$ to avoid $\mathrm{Y}$ ) and making objective changes, one can have a feeling, for instance, of being skilled enough through the creation of new meanings. That question is also discussed above.

Moreover, the $\mathrm{P}$ case shifts the attention to the plurality of perspectives and to the coordination of different I positions in the self-whole. Becoming a psychologist during the studies as well as being a psychologist in formal relations means to act in inherently ambivalent conditions in which a person is guided to different directions: I (me) as a person $<>$ I (me) as a psychologist. The presence of the ambivalence creates tensions that are coped with by the use of semiotic devices that, as we saw, can be developed especially for that purpose. Thus, the ambivalence that marks co-presence of differently orientated processes within the same whole (Abbey $\&$ Valsiner, 2004) can be conceived of as a developmental force (Kullasepp, 2008b) while it brings an additional possible direction into the ontogenesis of the self. New signs that are created by the self during becoming a psychologist begin to regulate psychological functioning and reveal a person's relations with the surroundings in a role-specific way. The problem that an inexperienced psychologist may encounter concerns the regulation of different subsystems of the self "me as a person" and "me as a psychologist" to eliminate the tension that rises due to the plurality of voices (professional $<>$ traditional common sense), dialogue of which feeds into the feeling of insecurity.

\section{The inter-individually different linkage of personal culture with role expectations}

The creation of an identity is not only the process of the creation of novelty in time. As it is well known in psychology, identity also refers to the continuity, to the feeling of sameness that is maintained 
under conditions where changes are called into existence. Becoming oneself is also the process of remaining, maintaining an emerged state of a system (Valsiner, 2000). Thus, to understand the formation of the self, it is important to illuminate how the sameness could reflect in the process of becoming. For that, the focus was shifted on the guiders of the construction of I position, "me as a psychologist."

An identity can operate as the compass orientating a person in the world of various opportunities. Navigating in the landscape of choices, we can feel that some of the directions are more appealing and fit with our interests more than others. By moving along the path of life people construct meanings of the surroundings that reveal their relations with them. For some, higher education is the one and only option to design a future. They are guided by certain values that shed light on their inclination to be related to the world in a certain way. It is argued that that future-oriented extension can come through signs of sufficient abstractness that operate as promoter signs that canalize future actions and become internalized in the form of feelings (Valsiner, 2007). Thus, when making decisions, persons can be guided by their affects, and choices can be made on the basis of emotional bound with $\mathrm{X}$ direction of life (I like it, I want it, I go for it), and can be more or less accessible for verbalization. Sometimes we cannot be sure why we have taken the particular "road" to go along (I don't know why I like it). Certainly the world where we live is always with limitations and choices are confined by different factors. What choices are made depends on the field of external factors (e.g., I like X, but it is impossible to do it under these circumstances) and inner tendencies (e.g., I like something and I go for it): I would like to study medicine, but due to $\mathrm{X}$ it is impossible.
Above we already discussed the part of the internalized representations of a psychologist that contain information about the future (desired, ought to be) self and that were taken as the basis for the creation of novelty in identity (e.g., I should be more tolerant). But longitudinal research design of this study also enabled us to focus on the entry into the role over a five year period, and to observe the emergence of sameness in trajectories-the tendency to persist in life course patterns (Sato et al., 2007), and the dynamics of rejection-acceptance of possible directions of trajectories available in the socio-cultural environment. The collected data enabled us to assume that personal image of a professional psychologist working in X field (counselor, school psychologist, etc.), and the person's relation with it, were involved in making decisions regarding one's professional path.

To make sense of a professional identity construction over time as the result of interactions between an internalized cultural material (the created meanings' complex of a psychologist) and the self, the focus was shifted on the obligatory passage points (OPP) - a phase or event which persons inevitably experience (Sato et al., 2007)—in becoming a psychologist. For defining the OPPs in this study, the understanding of inevitability of making decisions before arriving and after passing the equifinality point/period (EFP; studies in university) was taken as a basis. OPP 1 marks the decision to study psychology before enrollment in university, and OPP 2 refers to making decision after obtaining a bachelor degree concerning further professional and/or academic activity (including the specialization in master's program). OPP 1 and OPP 2 were conceived of as qualitatively different points of setting up further directions due to the knowledge they had about psychologists' professional role. It 
was assumed that students' decisions in OPP 2 allow taking a closer look at the linkage of the personal culture with professional role expectations, while familiarity with the field increases.

\section{Promoters of studies of psychology}

Students' responses illustrate that the EFP was reached through different initial conditions, which is one of the central/fundamental ideas of TEM (Sato et al., 2007). Below data from eleven students who were questioned over five years are presented. On the basis of their reports collected in the 1st year of studies in bachelor's program, two main groups could be formed. Group A was characterized by their reported prolonged interest toward the field of psychology for various reasons, among which giving or getting help, learning more about human conduct dominated, whereas students in group B did not stress deep and long-term interest. Examples (group A, six students):

Student E: "I wanted to know more than other people do, also about the reasons of behavior, to understand myself, to change my thinking style, behavior, to learn how to help myself; it is interesting to communicate/socialize with people."

Student P: "I decided to study psychology because I was interested [in 6th grade]. I noticed that I am friendly, and ready to help. I like to be surrounded by people. I think that I wanted to help."

Student F: "I became interested in psychology quite early, in 9th grade. It tended to be interested in understanding myself better. In high school we had classes, and now I became interested. My interest increased while I saw that so many young people have serious problems."

Becoming a psychologist can be conceived of as a process that does not begin, as our study shows, with the enrollment in university, but earlier. Certain values, likes or dislikes and beliefs could promote certain actions that culminate in the idea of becoming a psychologist (as well as a doctor, policemen, parent, etc.). We can assume that the construction of the direction of "becoming a psychologist" and many activities relevant to that trajectory are initiated by promoter signs that are argued (Valsiner, 2007) to operate as personal value-orientation. Among the students there were persons whose relations with their surroundings were flavored by promoter signs labeled as prosocial orientation (e.g., a wish to give help) and an interest in developing themselves. These reported reasons for studies were not that explicit in the responses of group B.

Examples (group B, five students):

Student G: "Actually I did not know for a long time what to study. The only thing I knew was that it must be to do with people."

Student H: "I had never planned to study psychology. But finally I decided in favor of humanities, because I understood that actually I am a people's person [natural communicator]."

Student I: "I was a little bit attracted to psychology, it wasn't boring. At the end of summer I was convinced that I want to study psychology. I began to like psychology because I knew that it will be useful to me in the future, in every sphere of life."

Students who formed group B did not refer to a long-term interest (e.g., "it wasn't boring") while the general social orientation ([interest in others ?] "it must be to do with people," "I am people's person") was represented.

\section{"I have earned a BSc in psychology, what next?!"}

After obtaining a BSc, different directions at the OPP2 are available for young people who can a) continue studies in a master's program (specializations in clinical psychology, in school psychology, 
Table 2 Decision at the OPP2

\begin{tabular}{|c|c|}
\hline Students who distanced themselves from the field of psychology & $\begin{array}{l}\text { Students who remained in a field closely linked with psychology, } \\
\text { but did not continue in the field of psychology }\end{array}$ \\
\hline $\begin{array}{l}\text { Student I: "Too much interactions and listening, you must be open, } \\
\text { I prefer to work with numbers... When a psychologist makes a } \\
\text { mistake then no one sees it, but in documents it is visible for every- } \\
\text { one" } \\
\text { Student J: "I cannot stay in the background as a psychologist } \\
\text { should do when interacting with the client/patient... I want to say } \\
\text { directly to the client what the client is doing in a wrong way" }\end{array}$ & $\begin{array}{l}\text { Student H: "I would like to say directly to people what they are } \\
\text { doing in a wrong way, I don't like that kind of counseling that X in- } \\
\text { troduced to us in classes. X frequently repeated what we are allowed } \\
\text { and not allowed to say... I don't like to control myself"... "Listening } \\
\text { to another person has become more and more unpleasant for me" } \\
\text { Student G: "I am too weak for clinical work" }\end{array}$ \\
\hline
\end{tabular}

in social psychology), b) start working in the field of psychology, or c) distance themselves from the field of psychology. While moving through EFP, students were exposed to influences from curriculum, they became more familiar with the field, and had a possibility to relate themselves to the role of a psychologist. It was expected that at the OPP2 the linkage between the personal culture and the professional role appears in decisions.

Reports in Table 2 illustrate that the perceived consistency/inconsistency between the promoter signs and the personal representation of a psychologist shaped further professional choices. On the bases of eleven students' reports, four different patterns of constructed relation with the role of a psychologist were revealed: enduring (five students; previous interest in the field and role endured over years), emerging (two; without previous prolonged interest in the field, interest toward the role of psychologist emerged during studies), disappearing (two; interest in the field and role diminished over years), absent (two; interest in the role was missing over years).

After years of socialization through the role of a psychologist, four of the eleven students rejected the role of a psychologist. Based on their responses we can observe that the conflict arose due to the regulations of professional conduct (e.g., to be open). However, the students' reports who remained in clinical/counseling psychology pointed to the possibility to do a "really meaningful job," and "give something to the world," thus demonstrating the linkage between value-orientation and the professional role.

Five of eleven students continued in the field in which they had prolonged interest. It seems that in some sense we can conceive of the role of a psychologist as a device that is in use to continuously recreate the directions of the present (and consequently the previous) identity, maintaining the features (X-oriented values) that may contribute to the feeling of sameness in time. It can be viewed as a conservative tendency that appears in the maintenance of the coherence between the past, present and the future self under conditions when the system is going through changes.

Case of $\mathrm{F}$ :

- (2005 spring) "I was interested in understanding myself better." "I decided a long time ago that I want to study psychology, it was in the 9th grade. Since then I have not had other plans. I want to become a counselor [my friends said that I am crazy, that I am the person who takes everything in, and how I can manage all this]. I want to work with younger people."

- (2010, After obtaining a bachelor degree) "I 
had a temporary job... preparing documents, like a secretary. I noticed that this time I dedicated myself more and more to on-line counseling." ( $\mathrm{F}$ was also involved in this activity during her studies.)

- "When I was offered a job as an X of a counseling center I didn't have any doubts. Even if I was still afraid of coming back to the university I knew that I wanted to stay in psychology. I have always had the wish to continue my studies of psychology, but I have also had doubts. I am afraid of the 'real counseling', sometimes I see psychologists who are burnt out. It is scary.'

- "I used to be more like a person who wanted to change the world into a better place, but now I am more realistic. I want not to help so much, but to support. You cannot help everyone." (repeated many times during the interview)

- (About the possible orientation toward science) "Seems that I need more interactions (communication)."

- "During studies I did web-counseling, and worked with people suffering from mental disorders."

- (What confirms that your choice is right?) "All this process, that I help someone on the web; I like reading psychology books-it shows that I still have interest-it means that this is the right thing to do."

The case of $\mathrm{F}$ demonstrates the constancy of the inclination toward clinical/counseling psychology. Regardless of the decision not to continue studies in a masters' program ( $\mathrm{F}$ frequently indicated during the interview to the fear of burnout), $\mathrm{F}$ preserved an interest in the field over years and found possibilities to be connected with an activity that was consistent with presumable promoter signs. Thus, besides the creation of novelty in self through the professional role (perceived increase in tolerance, empathy, etc.), students also re-created the already existing directions of the self that kept their relations with the surroundings similar.

\section{Conclusion}

To study psychology, as our study illuminates, is far more than acquiring professional knowledge and skills. This is the movement into the new social position that reflects in intra-psychological dynamics, evokes changes in interpersonal relations, and feeds into creation of new meanings.

Students' migration into the new environment of institutional representations led to the construction of personal culture that, in terms of meaning making (Valsiner, 2007), reflects in a subjectively constructed personal meanings that are projected into the world, and begin thereafter to regulate one's psychological functioning. Students' images of a psychologist changed over the five years and showed the decline in a tendency to idealize psychologists. Representations that students hold depicted psychologists as different from non-psychologist not only in skills and knowledge relevant to professional work, but also in personality features and arranging private sphere of life.

Our conclusion is that there was the influence of the image of clinical psychologists' work and common/everyday knowledge of the formation of the content of students' representations, of the emergence of I position (me as a psychologist), and of the reactions to clients/patients in informal relations. Exaggeratedly speaking, the "voice" of common knowledge tells what professionals should do, and they do.

This study revealed the image-based development which means that the understanding of a psychologist acquires significance while it sets up di- 
rections of development and is crucial at the professional settings. However, there was a general tendency among students to extend the self toward positively valued characteristics in the society, to link some features of the role with the self: an inclination toward prosocial direction, etc. Students' willingness to go through changes indicates the readiness for personal growth. As discussed above, it can culminate not in objective (expected) changes in skills and features, but in the construction of an understanding of a new Me (a more tolerant me). Adjustment to the new role, as our data illuminated, made the self construct semiotic control systems that regulated one's relations with the objective world. Consistent with previous researches that revealed changes in the selves of psychology students, and an internal need of future psychotherapists to behave morally, ethically (VanZandt, 1990; Johnson \& Campell, 2002) we found a similar trend among students who tried to meet others' higher moral standards set for as psychologists in informal settings (e.g., to keep secrets while friends expect it), or strived toward that direction (e.g., to follow the rule of confidentiality in everyday life). The longitudinal study shed light on the dynamics of the linkage of the personal culture with the expected features of professional role. Four different patterns of constructed relation with the field of psychology and with the role of psychologist were revealed (enduring, emerging, disappearing, absent). Thus, the studies of psychology can be commenced from different initial conditions, and in some cases the readiness for the professional role of a psychologist may not appear during studies. But, the inclination to be socially orientated (interest toward human issues), and the linkage with selected features of the role that reflected in extension of the self was common to all students. Yet, it did not guarantee the continuation in the chosen field after studies. For a deeper understanding of developmental phenomena the studies on dynamics of developmental trajectories have to focus on the conditions that initiate changes in directions. This study charted out the dynamics of the microgenesis-the process of emergence of novel formsof psychological phenomena revealing that the entry into the professional role of a psychologist embraces the formation of new aspects of the self and the recreation of meanings as the result of dialogical relations with surroundings.

\section{References}

Abbey, E., \& Diriwächter, R. (2008). Innovating genesis: Microgenesis and the constructive mind in action. USA: Information Age Publishing, Inc.

Abbey, E., \& Valsiner, J. (2004). Emergence of meaning through ambivalence. FQS (On-line journal) 6 (1) Art. 23 Available at http://www.qualitative-research.net/fqsrests/1-05/05-1-23-e.htm.

Baumeister, R. F. (Ed.) (1999). The self in social psychology. USA: Taylor \& Francis.

Bruss, K., \& Kopala, M. (1993). Graduate school training in psychology: Its impact upon the development of professional identity. Psychoterapy, 30, 4, 685-691.

Hacking, I. (2000). The social construction of what? USA: Harvard University Press.

Hamaker, E., L., Dolan, C., V., \& Molenaar, P. C. M. (2005). Statistical modeling of the individual: Rationale and application of multivariate stationary time series analysis. Multivariate Behavioral Research, 40, 2, 207-233.

Hermans, H. J. M. (1995). Voicing the self: From Information Processing to Dialogical Interchange. Psychological Bulletin, 3, 1-20.

Hermans H. J. M. (2001). The dialogical self: Toward a theory of personal and cultural positioning. Culture and Psychology, 7, 3, 243-281.

Hermans H. J. M. (Ed.). (2002). Special issue on dialogical self. Theory \& Psychology, 12(2), 147-280.

Hermans, H. J. M., Kempen, H. J. G., \& van Loon, R. J. P. (1992). The dialogical self. American psychologist., 47, 23-33. 
Johnson, W. B., \& Campbell, C. D. (2002). Character and fitness requirements for professional psychologists: Are there any? Professional Psychology: Practice and Research, 33, 1, 46-53.

Kullasepp, K. (2008a). Dialogical becoming: Professional identity construction of psychology students. Tallinn University.

Kullasepp, K. (2008b). Are you like this... or just behave this way? International Journal of Dialogical Science, $\mathbf{2}$, 1.

Kullasepp, K. (2011). Why become a "Shrink"? Psychology studies as an extension of self, In S. Salvatore, J. Valsiner, J. T. Simon, \& A. Gennra (Eds.), Yearbook of Idiographic science. Vol. 3. It: Firera \& Liuzzo Group. pp. 95-114.

Lotman, Y. M. (1990). Universe of the mind: A semiotic theory of culture. Bloomington: Indiana University Press.

Molenaar, P. C. M. (2004). A manifesto on psychology as idiographic science: Bringing the person back into scientific psychology, this time forever. Measurement: Interdisciplinary Research and Perspectives, 2, 210-218.

Sato, T. (Ed.) (2009). Qualitative study starting from Trajectory and Equifinality Model (In Japanese). Seishin Shobo.

Sato, T., Yasuda, Y, Kido, A., Arakawa,. A, Mizoguchi, H., \& Valsiner, J. (2007). Sampling reconsidered: Personal histories-in-the-making as cultural constructions. In J. Valsiner \& A. Rosa (Eds.), Cambridge handbook of socio-cultural psychology. New York: Cambridge Univer- sity Press. pp. 82-106.

Simão, L. M., \& Valsiner, J. (Eds.) (2006). Otherness in question: Labyrinths of the self. Greenwich, Ct.: Information Age Publishers.

Valsiner, J. (2000). Culture and human development. London: Sage Publications Ltd.

Valsiner, J. (2001). Comparative study of human cultural development. Madrid: Fundacion Infancia Aprendizaje.

Valsiner, J. (2007). Culture in minds and societies. New Delhi: Sage.

Valsiner, J., \& Rosa, A. (Eds.) (2007). The Cambridge handbook of sociocultural psychology. NY: Cambridge University Press.

Valsiner, J., \& Sato, T. (2006). Historically Structured Sampling (HSS): How can psychology's methodology become tuned into the reality of the historical nature of cultural psychology? In Straub, Kölbl, Weidemann and Zielke (Eds.) Pursuit of meaning: Advances in cultural and cross-cultural psychology. Transcript Verlag. pp. 215252.

VanZandt, C.E. (1990). Professionalism: A matter of personal initiative. Journal of Counseling and Development, 68, 243-245 (In K. Bruss \& M. Kopala, (1993). Graduate school training in psychology: Its impact upon the development of professional identity. Psychoterapy, 30(4), 685-691).

Vygotsky, L. S. (1987). Thought and language. 2nd ed. Cambridge, Ma: MIT Press. 